\title{
Neonatal Screening for Severe Combined Immunodeficiency (SCID)
}

\author{
Jennifer M. Puck, M.D. \\ Department of Pediatrics, University of California San Francisco and UCSF Benioff Children's \\ Hospital, San Francisco, CA
}

\begin{abstract}
Purpose of review-Population-based newborn screening for severe combined immunodeficiency (SCID) and related disorders has been instituted in five states, with several more planning to add this testing to their newborn screening panels. This review summarizes the rationale, development, and implementation of SCID screening programs to date and highlights current and future challenges.
\end{abstract}

Recent findings-Early results of T-cell receptor excision circle (TREC) testing newborns in pilot states indicate that this addition to the newborn screening panel can be successfully integrated into state public health programs. The TREC test has clinical validity and TRECs, as predicted, are an excellent biomarker of poor T-cell lymphocyte production in the thymus or increased lymphocyte loss resulting in T-cell lymphopenia. A variety of cases with typical SCID genotypes and other conditions have been detected in a timely manner and referred for appropriate early treatment.

Summary-Early detection of primary immunodeficiency is recognized as important for avoiding infectious complications that compromise outcomes. Routine screening of all newborns with the TREC test, implemented as part of an integrated public health program, can achieve presymptomatic diagnosis of SCID and other disorders with T-cell lymphopenia, allowing prompt and effective treatment and leading to a better understanding of the spectrum of these disorders and how to manage them.

\section{Keywords}

primary immunodeficiency; T cell receptor excision circle (TREC); severe combined immunodeficiency (SCID); T-cell lymphopenia; dried blood spot; newborn screening

\section{Introduction}

Newborn screening has grown from the original test for phenylketonuria developed by Robert Guthrie in 1963 [1] to a major effort supported and directed by each U.S. state's public health program. Rare but treatable conditions that would otherwise lead to significant morbidity and mortality are successfully identified by inexpensive tests, almost all making use of drops of infant blood applied to filter paper. Up to 50 or more metabolic disorders,

Contact information: Jennifer Puck, M.D., University of California, San Francisco, Box 0519, 513 Parnassus Avenue, HSE 301A, San Francisco, CA 94143-0519, puckj@peds.ucsf.edu, Phone: 415 476-3181, FAX: 415 502-5127.

Publisher's Disclaimer: This is a PDF file of an unedited manuscript that has been accepted for publication. As a service to our customers we are providing this early version of the manuscript. The manuscript will undergo copyediting, typesetting, and review of the resulting proof before it is published in its final citable form. Please note that during the production process errors may be discovered which could affect the content, and all legal disclaimers that apply to the journal pertain. 
hypothyroidism and hemoglobinopathies have now been incorporated into dried blood spot testing of newborns in most states, with the current status of each state's program summarized in reference [2*].

Within the past few years the first primary immune disorder, severe combined immunodeficiency (SCID), and related conditions with low numbers of T cells, have become amenable to identification by newborn screening. SCID screening is the first addition to the nationally recommended Uniform Screening Panel, following a new evidence-based review process [3]. It is also the first newborn screening test to use DNA as the primary analyte. This review summarizes the rationale, initiation process, early results in pilot states, and future challenges presented by universal screening for SCID.

\section{Evidence for adding SCID to the panel of newborn screening tests}

The US Advisory Committee on Heritable Disorders in Newborns and Children was established in part to work toward uniform, evidence-based newborn screening in what has previously been a patchwork of individual state programs [3]. The Advisory Committee solicits nominations of conditions to be added to newborn screening, commissions an independent review of evidence, and gathers input from stakeholders; upon arriving at a determination, it reports to the Department of Health and Human Services (DHHS) Secretary. SCID was first nominated in 2008, and evidence was assembled and reported in 2009 and 2010, at which time it was considered strong enough to merit a formal recommendation [4**]. Secretary of DHHS Kathleen Sibelius endorsed SCID screening in May, 2010.

SCID includes more than 10 genetic disorders characterized by profound defects in both cellular immunity and specific antibody production, and is estimated to occur in $1 / 50,000$ to $1 / 100,000$ births. All SCID infants have absent or extremely low production of antigenically naïve $\mathrm{T}$ cells from their thymus. The combined defects of $\mathrm{T}$ and $\mathrm{B}$ cells, plus absent NK cells in some forms of SCID, severely compromise an infant's ability to resist infections. Thus, it has long been clinically identified as infants without HIV infection who present with Pneumocystis jiroveci pneumonia and other bacterial, fungal and viral infections and failure to thrive, which is most often due to persistent enteric infection.

The rationale for SCID newborn screening, outlined in Table 1, centers on the facts that SCID is potentially treatable, but is infrequently recognized effectively prior to onset of devastating infections. SCID infants do not survive unless provided with functional immunity, but this can be achieved by hematopoietic cell transplantation (HCT) from a healthy donor [5*], by enzyme replacement in cases of adenosine deaminase (ADA) deficiency [6], and (although still experimental) by gene therapy for X-linked and ADA deficient SCID [7*] (see article by Booth and Thrasher in this issue). Infants with SCID are healthy at birth and initially protected by transplacentally derived maternal IgG antibodies, but typically develop severe and opportunistic infections by age 4 to 7 months. Repeated observations have shown superior outcomes in SCID infants diagnosed at a young age, particularly those fortunate enough to have an affected relative to alert health providers of the diagnosis [8-13].

The first suggestion that screening infants for lymphopenia could identify SCID in time for lifesaving treatment was by Buckley et al. in 1997 [8*]. Further retrospective analysis of cases treated by Dr. Buckley at Duke [11], and in England [12**], underlined the better survival of SCID infants diagnosed before developing infections. While the above studies from transplant centers showed a clear benefit for early diagnosis, a family based survey by the Immune Deficiency Foundation and Chan et al. found even more striking differences due to higher mortality of SCID infants not recognized at birth: Half of the deceased infants 
were either not diagnosed pre-mortem, or were too ill to be transferred to a tertiary center for specialized treatment [13*]. Furthermore, confirmation that $>80 \%$ of SCID infants were the first known to be affected in their family indicated that family history taking would not be helpful in diagnosing most cases of SCID. Additional rationale for the pursuit of newborn screening came from mathematical modeling by two methods, which showed that a sensitive, specific, and economical newborn screening test for SCID would be likely to be cost-effective $\left[14,15^{*}\right]$.

Another important development was the institution, beginning in 2006, of live attenuated rotavirus vaccination of infants at 6 weeks to 2 months of age. Infants affected with SCID whose diagnosis was not recognized received the vaccination and developed severe diarrheal disease due to vaccine-strain rotavirus $\left[16,17^{*}\right]$. While the vaccine is specifically contraindicated in immunodeficient infants, there is no way to know whether a healthyappearing infant at that age has SCID, other than by performing an immunological blood test. Newborn screening for SCID thus became an important consideration to balance the public health benefit of protection from rotavirus-induced diarrhea against the harm of vaccine-strain rotavirus infection caused in rare infants lacking adaptive immunity.

\section{The TREC test for SCID using newborn dried blood spots}

A breakthrough for the actualization of population-based newborn screening for SCID was the development of a screening test that could be performed using the dried blood spot samples already collected by US state screening laboratories for routine newborn screening for other conditions. Proposed screening methods have included absolute lymphocyte count (requiring a separate liquid blood sample [8], IL-7 immunoassay [10], bead-bound antibodybased detection of T-cell proteins CD3, CD4 and CD5 [18], and gene resequencing arrays [19]. However, to date the only assay with adequate sensitivity and specificity is the T-cell receptor excision circle (TREC) assay, first published in 2005 by Chan and Puck [20]. Late in maturation, $70 \%$ of thymocytes that will ultimately express $\alpha \beta-\mathrm{T}$ cell receptors form a circular DNA TREC from the excised TCR $\delta$ gene that lies within the TCR $\alpha$ genetic locus [21]. The circles are stable but do not increase following cell division and, therefore, become diluted as $\mathrm{T}$ cells proliferate. A quantitative polymerase chain reaction (PCR) reaction across the joint of the circular DNA provides the TREC copy number, a marker of newly-formed, antigenically-naïve thymic emigrant $\mathrm{T}$ cells.

Normal newborns have TREC numbers at $\sim 10 \%$ of their total T-cell numbers, whereas older children and adults have progressively lower ratios of TRECs to T cells, reflecting peripheral T-cell expansion [21]. Infants with SCID, sampled both at diagnosis and upon recovery of neonatal dried blood spots, were shown to have very low or undetectable TRECs (Table 2) [20,22]; even maternal T cells present in an infant with SCID, which occurs in up to $50 \%$ of cases, do not falsely raise the TREC count to the normal range because maternal cells have very few TRECs. Thus, a normal number of TRECs is an excellent biomarker for new autologous T-cell production, provided the DNA is adequate for PCR (shown by amplification of a control, such as a segment of the $\beta$-actin gene).

\section{Initial SCID screening programs}

The TREC test was first scaled up and adapted to a statewide newborn screening format by Baker et al. in Wisconsin [23]. Other states, including Massachusetts, have devised their own adaptations of this assay [24]. Each state has tailored their TREC screening according to individual program structure and requirements. The Wisconsin program, which began in 2008 , was recently described [25**]. A clinical study of TREC screening is also under way in selected hospitals on the Navajo Indian Reservation, since Navajo Native Americans are 
known to have a high rate of SCID due to a founder mutation in the DCLRE1C (Artemis) gene [26].

California, with over 500,000 births per year and a very diverse population, has completed one year of its development program of TREC screening of all newborns; its algorithm is shown in Figure 1 [J. Puck and F. Lorey, unpublished]. Because the test is now considered standard care, no special parental consent is required. A TREC quantitative PCR similar to those of the Wisconsin program is followed by a $\beta$-actin gene PCR control only if the TREC number is inadequate. If both TREC and control DNA copy numbers are below the cutoff value after two separate DNA extractions, the sample is considered a "DNA Amplification Failure" (DAF), and a second heelstick blood sample is requested from the baby. Premature and ill infants in intensive care units have their own DAF cutoff values. All samples with undetectable or below-cutoff TRECs and an adequate $\beta$-actin control PCR are considered positive. Infants with a positive screening test result or two DAF samples require second tier testing with T-cell enumeration by flow cytometry.

An important feature of the California SCID screening program is that the liquid blood sample that follows an abnormal screening result is an integral part of the California Genetic Disease Laboratory public health program. Area service center staff work with providers and families so that blood is rapidly obtained at the newborn blood draw stations throughout the state that have been established for metabolic disease follow-up. All samples are sent to single central laboratory for a complete blood count, differential, and specified flow cytometry panel of lymphocyte subset markers, including naïve (CD45RA) and memory (CD45R0) T-cell markers. All results are interpreted by two designated immunodeficiency consultants for the program. In this way, infants receive a definitive diagnosis and are referred without delay to a center of excellence for further management.

The performance of the TREC test in California has been excellent, with no missed SCID cases to our knowledge and very few DAF samples (Table 2). Of only 50 liquid blood samples required (1 per 10,000 births), $40 \%$ proved to have true T-cell lymphopenia, indicating that TRECs are, as predicted, a very good biomarker. All infants with T-cell lymphopenia were under the care of a primary immunodeficiency expert by one month of age [J Puck, personal communication]. Tracking of cases by race and ethnicity has suggested a somewhat higher rate than expected of T-cell lymphopenia among Hispanics, and with the large California population it will be possible to stratify risks among different groups.

\section{Conditions detected by newborn screening}

SCID newborn screening programs have successfully identified a range of typical SCID and other conditions that would not otherwise have been identified before the onset of serious infections (Table 3). The first case of SCID was reported from Massachusetts after screening 100,000 infants [27**]. In addition to typical SCID, SCID-related disorders are increasingly appreciated, as found by the early Wisconsin experience [28]. Patients with hypomorphic SCID gene defects allowing residual function may have "leaky SCID" with later onset, or Omenn syndrome, with rash, adenopathy and oligoclonal, poorly functioning $\mathrm{T}$ cells with a memory surface phenotype.

In addition, severely affected patients with variant forms of SCID such as cartilage-hair hypoplasia could be expected to have abnormal TREC results because their T cells can be nearly absent. CHARGE syndrome, Down syndrome or DiGeorge syndrome, the latter usually with chromosome 22.11 deletion, can present with life-threatening infections in infancy due to T-cell deficiency, and have been identified by neonatal TREC screening $[28,29 * 30 *]$. RAC2 deficiency, previously known only as a granulocyte disorder, was 
diagnosed following newborn screening with low TRECs and T-cell lymphopenia [28], as was Jacobsen syndrome associated with an interstitial deletions of chromosome 11q. Siblings affected with DOCK8-deficient hyper-IgE syndrome with lymphopenia had undetectable TRECs during childhood, though newborn samples were not available [31*].

Secondary causes of T-cell lymphopenia, which include loss by extravasation or third spacing, lymphangiectasia or HIV infection, also predispose infants to opportunistic infections such as Pneumocystis jiroveci pneumonia and depending on the degree of lymphopenia might be found to have low TRECs upon newborn screening.

\section{Future directions and challenges}

The range of conditions detected by newborn screening remains to be determined, and their total incidence and relative proportions in different populations are yet to be defined. It may be useful to place cases with low or absent TRECs in the following categories (Table 3): (A) Typical SCID, defined by the Primary Immune Deficiency Treatment Consortium [32*] as fewer than 300 autologous $\mathrm{T}$ cells per microliter of peripheral blood and less than $10 \%$ of normal T-cell proliferation to the mitogen PHA [32,33]; (B) leaky SCID, with a hypomorphic mutation in a known SCID gene and T cells from $300-1500$ per microliter; (C) variant SCID, with no defined mutation and T cells from $300-1500$ per microliter, with impaired responses to mitogens; (D) multi-system syndromes with T-cell defects, such as DiGeorge syndrome; and (E) secondary T-cell defects, such as lymphangiectasia with T-cell sequestration and loss; some of these, such as lymphopenia associated with extreme low birthweight, may resolve over time. We expect that previously unrecognized conditions will come to light with screening.

How best to achieve B-cell as well as T-cell reconstitution in SCID infants remains controversial, with opinions divided as to whether cytoreductive or ablative vs. no chemotherapy conditioning should be used, and what type of donor hematopoietic stem cells are best, among other questions $\left[32,34^{* *}\right]$. Should SCID HCT treatment be done in a few centers of excellence, or does every state need to perform this treatment locally? What are the indications for ADA enzyme replacement or gene therapy as opposed to HCT? What laboratory workup is essential for very small infants with SCID who are healthy but can easily become anemic with repeated blood sampling? Fortunately the PIDTC has been funded to conduct prospective studies, and, eventually, clinical treatment trials on a multicenter basis, so that these and other questions can be answered $[32,33]$.

Extension of the concept of newborn screening for primary immunodeficiency would benefit patients with B-cell disorders, as well as those whose T-cell defects can be found by TREC screening. B-cell kappa chain excision circles have been suggested as an analyte, and preliminary work is promising [35,36*]. However the challenges of detecting differences between numbers of normal and abnormal kappa-deleting recombination excision circles (KRECs) with the small amounts of DNA recoverable from dried blood spots remain formidable.

Finally, controversies surrounding the collection, testing, storage. and utilization of dried blood spots from infants by state newborn screening programs have highlighted the need for better outreach and education of the public regarding the public health benefits of newborn screening. States need to be sure that their policies are clear and consistent [37*], and better information needs to be transmitted to the public. Perhaps this may be accomplished by better linking of prenatal obstetrical care and counseling to postnatal newborn screening as DNA based testing, started with TREC testing for SCID, becomes more widespread [38*]. Raising public awareness of rare disorders, including primary immunodeficiencies, is also an important activity in support of early diagnosis through newborn screening [39]. 


\section{Conclusion}

Newborn screening for SCID is being adopted by an increasing number of state public health programs following its successful initiation in Wisconsin, followed by Massachusetts, California, New York, Louisiana and Puerto Rico. Classic SCID, leaky SCID and Omenn syndrome, as well as additional recognized conditions with T-cell lymphopenia have been found, as well as cases with low T-cell production of unknown underlying cause. Forward screening makes possible determination of the true incidence and spectrum of SCID and related disorders for the first time. Prospective studies are needed to determine the optimal treatment protocols for very small, young infants with these disorders who have not developed infections.

\section{Key points}

1. SCID screening is justified because early identification is associated with more successful treatment and better outcome.

2. Newborns in several states are successfully being screened for SCID with a TREC test done on routine dried blood spots.

3. In addition to SCID, related conditions with low production or increased destruction of $\mathrm{T}$ cells are detected by TREC screening.

4. Population-based screening will permit determination of incidence, spectrum and optimal management of SCID and related conditions.

\section{Acknowledgments}

Thanks to Dr. Fred Lorey and colleagues at the California Dept. of Public Health and Genetic Disease Laboratory, and to Perkin Elmer and Quest Nichols Institute for design and conduct of testing; Drs. Joseph Church, Mort Cowan, Christopher Dvorak, Nina Kapoor, David Lewis, Sean McGhee, Ted Moore, E. R. Stiehm, Chu Ri Shin and Ken Weinberg for helpful discussions; and the Jeffrey Modell Foundation and NIH NIAID and ORD for support of PIDTC U54 AI082973, NICHD for RO3 HD 060311, NIAID for RO1 AI078248, and NCRR UL1 RR024131 for the UCSF CTSI.

Funding for this work was received from NIH (PIDTC, RO3, RO1, UCSF CTSI) and the Jeffrey Modell Foundation

\section{References}

1. Guthrie R, Susi I. A simple phenylalanine method for detecting phenylketonuria in large populations of newborn infants. Pediatrics. 1963; 32:318-343.

2. Newborn Screening Status Report (updated 3/01/10). National Newborn Screening and Genetics Resource Center. Accessed 26 Aug 2011http://genes-r-us.uthscsa.edu/nbsdisorders.pdf. Website that maintains an up-to-date record of state newborn screening program activity, with links to national policy and other current information.

3. Howell RR, Lloyd-Puryear MA. From developing guidelines to implementing legislation: actions of the US Advisory Committee on Heritable Disorders in Newborns and Children toward advancing and improving newborn screening. Semin Perinatol. 2010; 34:121-124. [PubMed: 20207261]

4. Lipstein EA, Browning MF, Green NS, et al. Systematic evidence review of newborn screening and treatment of severe combined immunodeficiency. Pediatrics. 2010; 125:1226-1235. Report of the independent panel assembled to weigh the peer-reviewed published evidence and expert advice regarding newborn screening for SCID.

5. Buckley RH. Transplantation of hematopoietic stem cells in human severe combined immunodeficiency: longterm outcomes. Immunol Res. 2011; 49:25-43. [PubMed: 21116871] Summary of long-term outcome, according to molecular type, of 166 consecutive SCID infants 
given non-conditioned related donor bone marrow transplants at Duke over the past 28 years, with a comparison to published reports of long-term outcomes of transplants at other centers.

6. Gaspar HB, Aiuti A, Porta F, et al. How I treat ADA deficiency. Blood. 2009; 114:3524-3532. [PubMed: 19638621]

7. Fischer A, Hacein-Bey-Abina S, Cavazzana-Calvo M. Gene therapy for primary adaptive immune deficiencies. J Allergy Clin Immunol. 2011; 127:1356-1359. [PubMed: 21624615] Over 10 years of experience with gene therapy for SCID shows sustained immune reconstitution is possible, but initial trials were marred by retroviral-induced leukemia; newer lentiviral vectors should provide safer and effective treatment, to be proved by ongoing clinical trials

8. Buckley RH, Schiff RI, Schiff SE, et al. Human severe combined immunodeficiency: Genetic, phenotypic and functional diversity in one hundred eight infants. J Pediatr. 1997; 130:378-387. [PubMed: 9063412] First observation that low absolute lymphocyte count could be used to screen infants for SCID, so as to identify the condition in time for lifesaving treatment before the onset of opportunistic infections.

9. Lindegren ML, Kobrynski L, Rasmussen SA, et al. Applying public health strategies to primary immunodeficiency diseases: a potential approach to genetic disorders. MMWR Recomm Rep. 2004; 53:1-29. [PubMed: 14724556]

10. Puck JM. SCID Newborn Screening Working Group. Population-based newborn screening for severe combined immunodeficiency: steps toward implementation. J Allergy Clin Immunol. 2007; 120:760-768. [PubMed: 17931561]

11. Myers LA, Patel DD, Puck JM, Buckley RH. Hematopoietic stem cell transplantation for severe combined immunodeficiency in the neonatal period leads to superior thymic output and improved survival. Blood. 2002; 99:872-878. [PubMed: 11806989]

12. Brown L, Xu-Bayford J, Allwood Z, et al. Neonatal diagnosis of severe combined immunodeficiency leads to significantly improved survival outcome: the case for newborn screening. Blood. 2011; 117:3243-3246. [PubMed: 21273302] This retrospective study from England confirms that SCID infants diagnosed early in life (based on positive family history) avoid pre-diagnosis serious infections and have superior survival and long-term outcomes following treatment

13. Chan A, Scalchunes C, Boyle M, Puck JM. Early vs. delayed diagnosis of severe combined immunodeficiency: A family perspective survey. Clin Immunol. 2011; 138:3-8. [PubMed: 21035402] A family-based, rather than referral-center-based, survey revealed that infants with SCID born to families with a prior affected relative had earlier diagnosis and better outcome than did sporadic cases, and that $50 \%$ of SCID infants without a positive family history died before or during attempted immune reconstitutive treatment.

14. McGhee SA, Stiehm ER, McCabe ER. Potential costs and benefits of newborn screening for severe combined immunodeficiency. J Pediatr. 2005; 147:603-608. [PubMed: 16291349]

15. Chan K, Davis J, Pai SY, et al. A Markov model to analyze cost-effectiveness of screening for severe combined immunodeficiency (SCID). Mol Genet Metab. 2011 Jul 12. [Epub ahead of print, PMID: 21810544]. A Markov model shows that even with very conservative estimates of disease incidence and test performance, universal newborn screening for SCID is likely to be a cost effective means to improve quality and duration of life for affected individuals.

16. Werther RL, Crawford NW, Boniface K, et al. Rotavirus vaccine induced diarrhea in a child with severe combined immune deficiency. J Allergy Clin Immunol. 2009; 124:600. [PubMed: 19660805]

17. Patel NC, Hertel PM, Estes MK, et al. Vaccine-acquired rotavirus in infants with severe combined immunodeficiency. N Engl J Med. 2010; 362:314-319. [PubMed: 20107217] Cases of SCID infants unintentionally infected with rotavirus attenuated vaccine, which caused significant clinical illness.

18. Janik DK, Lindau-Shepard B, Comeau AM, Pass KA. A multiplex immunoassay using the Guthrie specimen to detect $\mathrm{T}$-cell deficiencies including severe combined immunodeficiency disease. Clin Chem. 2010; 56:1460-1465. [PubMed: 20660143]

19. Lebet T, Chiles R, Hsu AP, et al. Mutations causing severe combined immunodeficiency: detection with a custom resequencing microarray. Genet in Med. 2008; 10:575-585. [PubMed: 18641513] 
20. Chan K, Puck JM. Development of population-based newborn screening for severe combined immunodeficiency. J Allergy Clin Immunol. 2005; 115:391-398. [PubMed: 15696101]

21. Douek DC, McFarland RD, Keiser PH, et al. Changes in thymic function with age and during the treatment of HIV infection. Nature. 1998; 396:690-695. [PubMed: 9872319]

22. Morinishi Y, Imai K, Nakagawa N, et al. Identification of severe combined immunodeficiency by T-cell receptor excision circles quantification using neonatal Guthrie cards. J Pediatr. 2009; 155:829-833. [PubMed: 19628217]

23. Baker MW, Grossman WJ, Laessig RH, et al. Development of a routine newborn screening protocol for severe combined immunodeficiency. J Allergy Clin Immunol. 2009; 124:522-527. [PubMed: 19482345]

24. Gerstel-Thompson JL, Baptiste JC, Navas JS, et al. High-throughput multiplexed T-cell-receptor excision circle quantitative PCR assay with internal controls for detection of severe combined immunodeficiency in population-based newborn screening. Clin Chem. 2010; 56:1466-1474. [PubMed: 20660142]

25. Chase NM, Verbsky JW, Routes JM. Newborn screening for T-cell deficiency. Curr Opin Allergy Clin Immunol. 2010; 10:521-525. [PubMed: 20864885] Description of initial SCID newborn screening programs, including patients identified and one successfully treated by transplantation, in the Wisconsin program.

26. Li L, Moshous D, Zhou Y, et al. A founder mutation in Artemis, an SNM1-like protein, causes SCID in Athabascan-speaking Native Americans. J Immunol. 2002; 168:6323-6329. [PubMed: 12055248]

27. Hale JE, Bonilla FA, Pai SY, et al. Identification of an infant with severe combined immunodeficiency by newborn screening. J Allergy Clin Immunol. 2010; 126:1073-1074. [PubMed: 20933257] The first case of typical SCID identified in the course the Massachusetts pilot program, after 100,000 infants had been screened. The infant with undetectable TRECs had JAK3 deficient SCID and was managed with home isolation, prophylactic immunoglobulin and antibiotics until receiving hematopoietic cell transplantation.

28. G.W. Routes JM, Verbsky J, Laessig RH, et al. Statewide newborn screening for severe T-cell lymphopenia. JAMA. 2009; 302:2465-2470. [PubMed: 19996402]

29. McDonald-McGinn DM, Sullivan KE. Chromosome 22q11.2 deletion syndrome (DiGeorge syndrome/velocardiofacial syndrome). Medicine. 2011; 90:1-18. [PubMed: 21200182] An up to date review of DiGeorge spectrum disorders, including immune features.

30. Ram G, Chinen J. Infections and immunodeficiency in Down syndrome. Clin Exp Immunol. 2011; 164:9-16. [PubMed: 21352207] A useful discussion of the range of immune abnormalities in Down syndrome

31. Dasouki M, Okonkwo KC, Ray A, et al. Deficient T Cell Receptor Excision Circles (TRECs) in autosomal recessive hyper IgE syndrome caused by DOCK8 mutation: Implications for pathogenesis and potential detection by newborn screening. Clin Immunol. 2011 Jun 21. [Epub ahead of print, PMID: 21763205]. Children with DOCK8 deficiency and T-cell lymphopenia were found to have low to undetectable TRECs.

32. Primary Immune Deficiency Treatment Consortium. [Accessed Aug. 28, 2011]http://rarediseasesnetwork.epi.usf.edu/PIDTC/SCID/index.htm This consortium of large and small centers treating SCID and other primary immunodeficiencies with cellular therapies has prospective and retrospective SCID studies under way that will help determine best practices for treatment.

33. Griffith LM, Cowan MJ, Kohn DB, et al. Allogeneic hematopoietic cell transplantation for primary immune deficiency diseases: current status and critical needs. J Allergy Clin Immunol. 2008; 122:1087-1096. [PubMed: 18992926]

34. Buckley RH. B-cell function in severe combined immunodeficiency after stem cell or gene therapy: A review. J Allergy Clin Immunol. 2010; 125:790-797. [PubMed: 20371393] A thorough and expert review of the world literature on this topic. Although bone marrow transplantation provides reliable T-cell immunity for SCID, B-cell recovery remains problematic. Pretransplantation conditioning does not guarantee that B-cell function will develop; therefore, one must decide whether there is justification for using agents that compromise innate immunity and have intrinsic toxicities to gain B-cell immune reconstitution. 
35. Imai, K., et al. TREC and KREC quantification for newborn mass screening of T cell deficiency and B cell deficiency. Symposium on Immunodeficiency: New Aspects of Primary Immunodeficiency, PAS/ASPR meeting; Apr 30-May 3, 2011; Denver, CO.

36. Sottini A, Ghidini C, Zaontti C, et al. Simultaneous quantification of recent thymic T-cell and bone marrow B-cell emigrants in patients with primary immunodeficiency undergone to stem cell transplantation. Clin Immunol. 2010; 136:217-227. [PubMed: 20452829] Methodology for determining recent $\mathrm{T}$ - and $\mathrm{B}$-cell maturation simultaneously is described; this could potentially be adapted for newborn screening for B-cell lymphopenic disorders.

37. Therrell BL Jr, Hannon WH, Bailey DB Jr, et al. Committee report: Considerations and recommendations for national guidance regarding the retention and use of residual dried blood spot specimens after newborn screening. Genet Med. 2011; 13:621-624. [PubMed: 21602691] The current patchwork of state public health laboratory policies and consent for future use of stored samples is reviewed and recommendations are outlined to safeguard privacy and autonomy concerns of the public, while protecting this valuable resource for program development and research on rare conditions.

38. Hiraki S, Green NS. Newborn screening for treatable genetic conditions: past, present and future. Obstet Gynecol Clin North Am. 2010; 37:11-21. [PubMed: 20494254] Newborn screening is a successful but complex public health program now entering the DNA age with severe combined immunodeficiency testing. Future screening with DNA may expand, shifting from a phenotypebased to a more genotype-based system that may benefit from linking prenatal records to neonatal screening and care.

39. Modell F, Puente D, Modell V. From genotype to phenotype. Further studies measuring the impact of a Physician Education and Public Awareness Campaign on early diagnosis and management of primary immunodeficiencies. Immunol Res. 2009; 44:132-149. [PubMed: 19140027] 


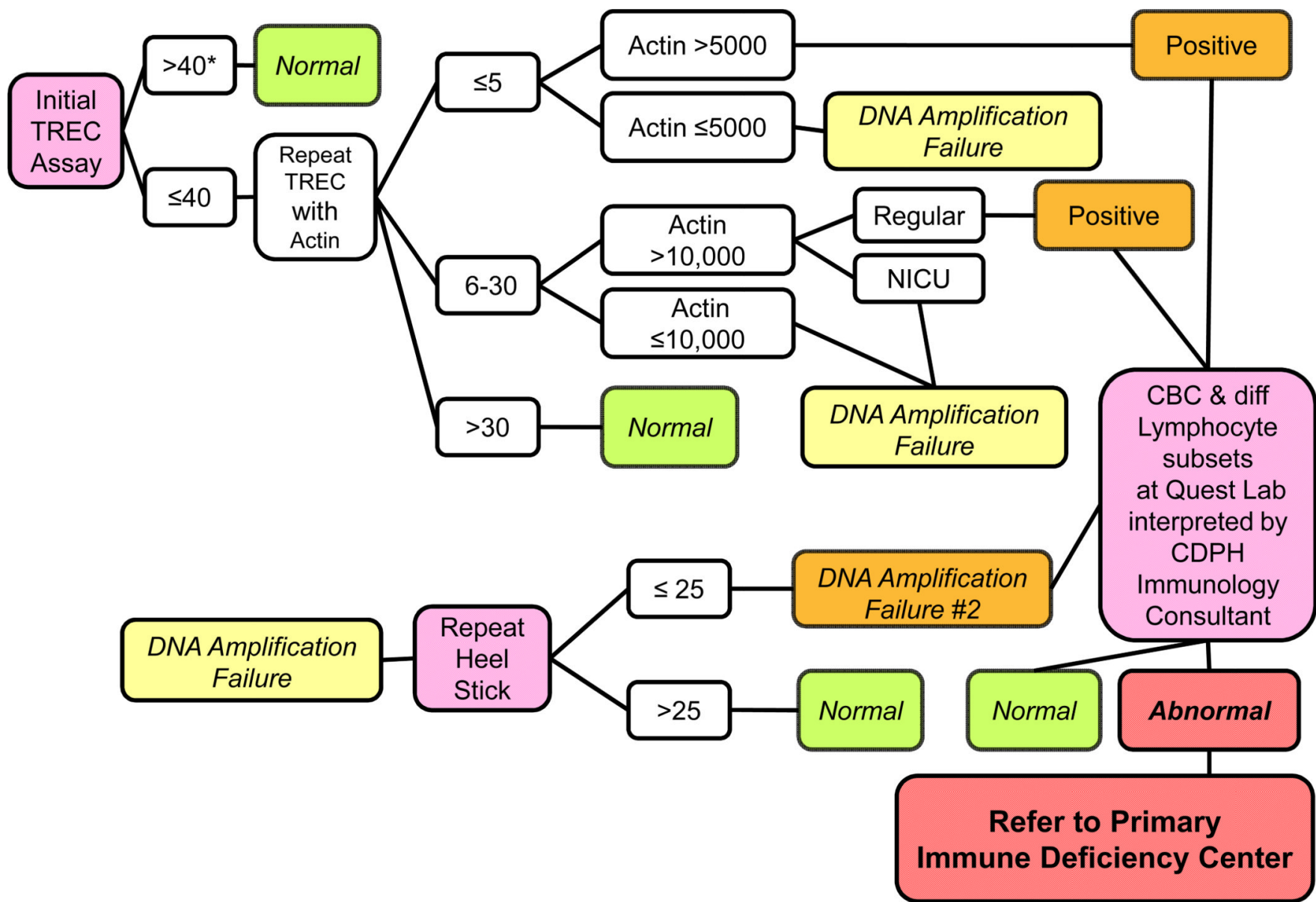

Figure 1.

California algorithm for newborn screening for SCID and related conditions.

*TREC and $\beta$-actin units are copies per 1/8" punch (equivalent to $\sim 3$ microliters of blood). 
Table 1

Rationale for newborn screening for SCID.

Importance of early identification:

Establish diagnosis and institute immediate lifesaving treatment.

Avoid inefficient, costly, dangerous 'diagnostic Odyssey'.

Provide families with genetic diagnosis and advice on reproductive risks.

Learn incidence and true spectrum of SCID.

Educate providers and public about SCID

Permit multicenter collaborative trials to determine optimal treatments.

Barriers to early diagnosis without screening:

SCID and related conditions are rare.

Infections are common in all infants, not just those with SCID.

Over $80 \%$ of cases are sporadic, with no family history.

Family history can be missed, or nonspecific.

SCID infants are protected by maternal IgG for their first months of life.

Because both a gene defect and environmental exposure are required for overt disease, presentation is variable. 
Table 2

Summary of California TREC screening experience in first year.

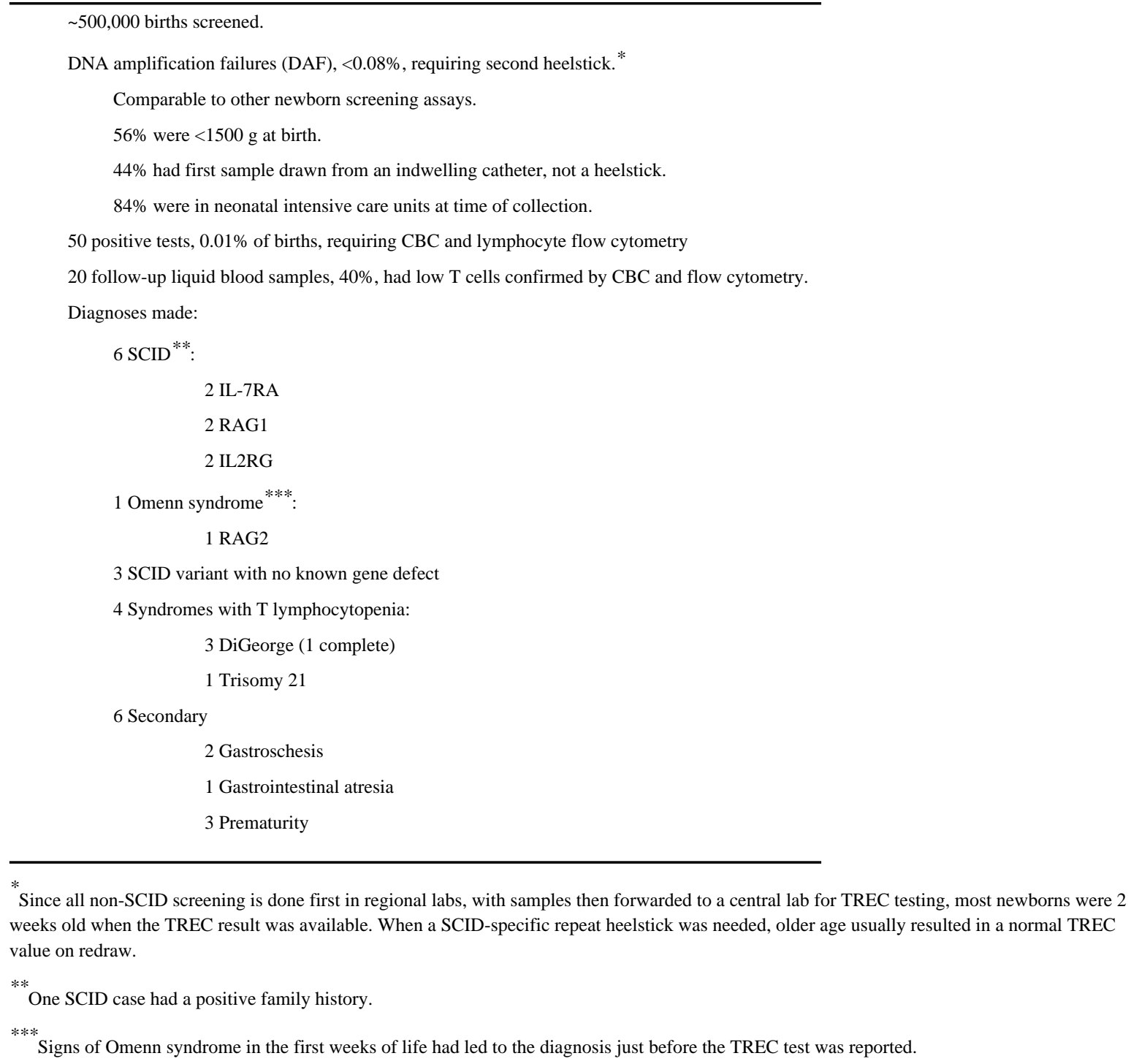

* Since all non-SCID screening is done first in regional labs, with samples then forwarded to a central lab for TREC testing, most newborns were 2 weeks old when the TREC result was available. When a SCID-specific repeat heelstick was needed, older age usually resulted in a normal TREC value on redraw.

*** One SCID case had a positive family history.

*** Signs of Omenn syndrome in the first weeks of life had led to the diagnosis just before the TREC test was reported. 
Table 3

Conditions detected by low or absent TRECs.

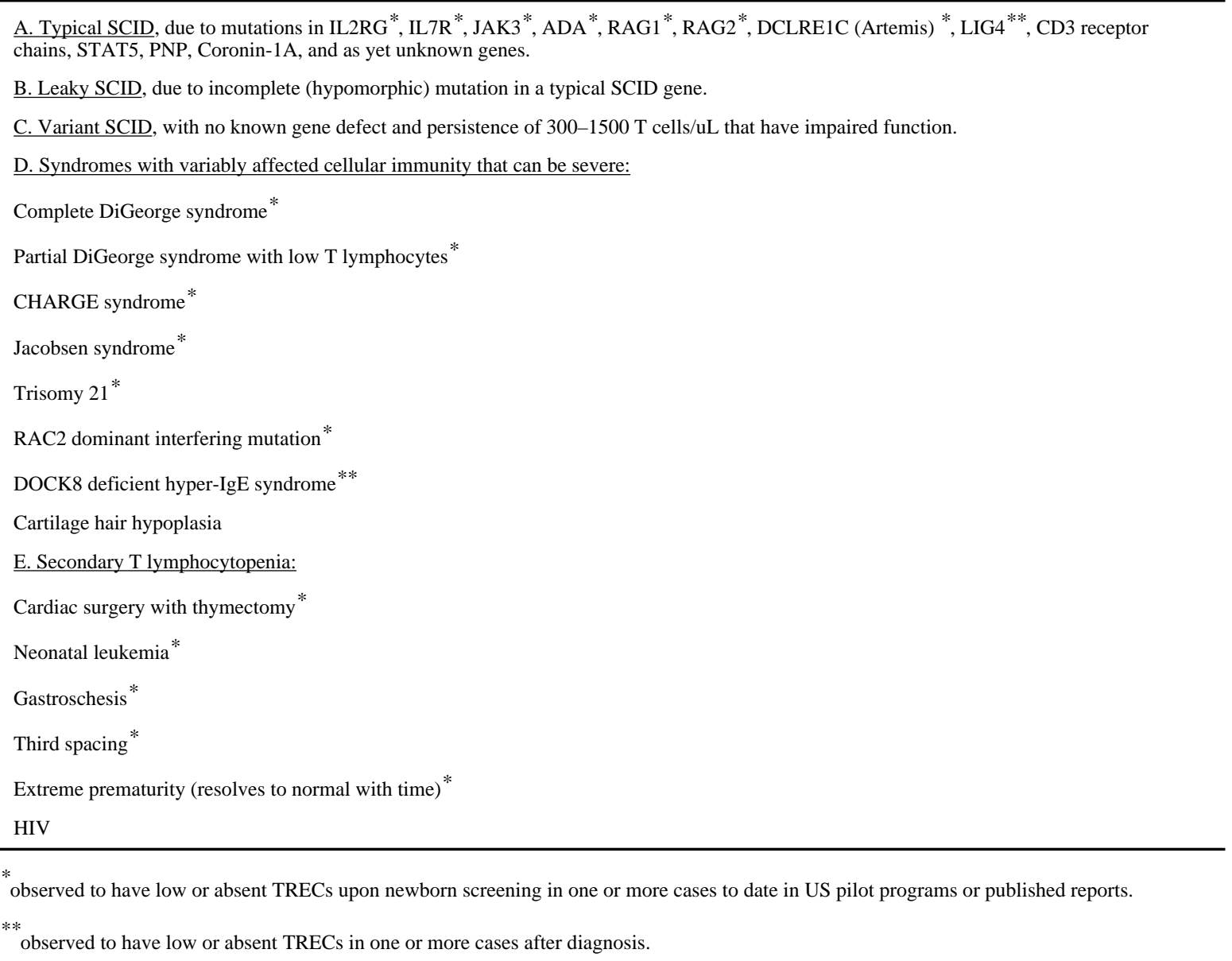

